\title{
Metabolic Syndrome and Lipid Metabolism Disorders: Molecular and Biochemical Aspects
}

\author{
Oksana Tkachenko ${ }^{1}$, Iryna Polishchuk ${ }^{2}$, Nadiya Gorchakova ${ }^{3}$, Hanna Zaychenko ${ }^{3}$ \\ ${ }^{1}$ Palladin Institute of Biochemistry, Kyiv, Ukraine \\ ${ }^{2}$ Igor Sikorsky Kyiv Polytechnic Institute, Kyiv, Ukraine \\ ${ }^{3}$ Bogomolets National Medical University, Kyiv, Ukraine
}

\section{SUMMARY}

The review highlights the characteristics of adipose tissue as a metabolically active organ, reveals endocrinous functions of adipose tissue and the role of adipose tissue in immune system's functioning. The role of obesity in the development of insulin resistance (IR) and diabetes mellitus type 2 and the effect of dyslipidemia on the development of metabolic syndrome (MS) and IR are given. It is shown that the main function of fatty tissue is energy storage via the maintenance of balance between lipolysis and lipogenesis processes. Inhibition of lipogenesis and enhancement of lipolysis are observed in metabolic disorders, in particular, IR. Adipose tissue's function is regulated by adipokines excreted by it. Inflammation condition is an essential constituent and one of the reasons of IR status. Neutralization of the main inflammatory cytokines does not restore sensitivity to insulin, which is indicative of the fact that inflammation condition is not the only cause of IR. Chronic low-grade inflammation develops as a result of obesity. Pro-inflammatory cytokines affect insulin signaling via stimulation of stress kinases. Functions of signal and immune cells are dependent on phospholipid composition. Unsaturated fatty acids are the substrate for synthesis of bioactive mediators. Allocated peroxisome proliferator-activated receptors (PPARs) are considered to be the main therapeutic target. Synthetic ligands of thiazolidinidones and components of the endogenous cannabinoid system of $\mathrm{N}$-acetylethanolamines, capable of interacting and binding to PPARs receptors, are investigated. N-stearoylethanolamine is of special interest; its positive effect on normalization of lipid profile of different tissues, particularly insulin-sensitive tissues, has already been shown.

Key words: adipose tissue, obesity, diabetes mellitus type 2, insulin resistance, fatty acids, endocannabinoid substances 


\section{INTRODUCTION}

Nowadays metabolic disorders represent a great danger for health and life of people. Diabetes mellitus (DM) or type 2 diabetes (T2D) is one of the metabolic diseases, spreading at high rate. Thus, according to prognosis of International Diabetes Federation and World Health Organization (1), 10\% of the planet population will suffer from diabetes by the year 2030, and $90 \%$ of diabetes cases will be classified as diabetes T2D, characterized by glucose homeostasis disorders and primary insulin resistance (IR) (2). The study of mechanisms of insulin resistance development underlies the creation of effective therapy of T2D. Development of pharmaceutical products for diabetes therapy is the area of extreme urgency, which is proven by large-scale R\&D projects by global pharmaceutical market leaders.

At present, a lot of attention is focused on dyslipidemia and inflammation process being the main mechanisms of IR acquisition. Obesity causes increase in dimensions of adipocytes and fat tissue hypertrophy. Consequently, adipose tissue of obese people is characterized by the presence of a large number of anti-inflammatory macrophages producing cytokines such as tumor necrosis factor $\alpha$ $(\mathrm{TNF} \alpha)$, interleukins (IL-1b, IL-6) and monocyte chemoattractant protein 1 (MCP-1). This causes the development of inflammation, which provokes disorders of lipogenesis and lipolysis balance. As a result, excess of circulatory fatty acids is observed. Fatty acid excess, therefore, enhances inflammation and provokes the development of dyslipidemia and oxidative stress. These processes influence directly and indirectly the interaction of insulin, insulin receptors and insulin receptor substrates. Insulin resistance develops as a result. Investigation of products, capable of affecting the lipid balance in general and fatty acid composition, in particular, is a promising direction in treatment of IR and T2D (3).

The purpose of our study was to analyze current data on the molecular and biochemical bases of such disorders as obesity, insulin resistance and dyslipidemia, which are the main constituents of metabolic syndrome and the deviations of lipid metabolism in human organism.

\section{Adipose tissue as a metabolically active organ}

Adipose tissue is a metabolically active organ. It is composed of adipocytes, which are the main fat cells, and stromal-vascular fraction, containing preadipocytes, blood cells, endothelial cells, and pericytes. Adipose tissue is considered to be an important immune and endocrine organ, as it synthesizes several bioactive substances, which regulate a large number of various biological processes.

There are two different types of fatty tissue in all mammals: white adipose tissue (WAT) and brown adipose tissues (BAT), which are different in terms of morphology and function. BAT is represented by cells with small droplets of fat. This cell type is almost absent in adults, but it is present is newborns. It is concentrated in axillary cavities, between shoulder blades and on posterior neck part (4). BAT color is explained by the presence of dense vascular network and a large number of densely packed mitochondria. These adipocytes express thermogenin gene UCP1 (uncoupling protein 1), which allows protons to penetrate into mitochondrial matrix without synthesis of adenosine triphosphate (ATP). Thus, the rate of cellular respiration is increased, and heat is generated. Adipocytes of brown fatty tissue are the sites of thermogenesis - the process of oxidation of fatty acids (FAs) by mitochondria with heat production.

WAT is comprised of cells containing large lipid droplets. WAT is found all over the body and detected in cavities of organs. Its functions are much more diverse and more complicated compared to the brown one. The tissue performs protective and heat isolation functions and represents the main regulator of lipid balance as it is capable of storing and releasing energy, mainly represented by triacylglycerol (TAG) and FAs.

Lipogenesis is the process of synthesis of fatty acids from acetyl-CoA, which occurs predominantly in adipocytes, and more rarely in the liver. FAs are supplied to adipocytes via fatty acid transporters. Insulin induces glucose uptake via the glucose transporter type 4 (GLUT4) to the plasmalemma. FAs are re-esterified with involvement of glyceryl-3phosphatase (glucose derivative) with formation of triglycerol (5). It has been proven that GLUT4 transfer to plasmalemma requires mandatory activation of phosphoinositide 3-kinase (PI3K), RAC-alpha serine/ threonine-protein kinase (AKT) and certain isoforms of protein kinase $C$ (6). Moreover, inhibition of activity of kinases PI3K/akt1 and PI3K/akt2 decreases differentiation of adipocytes. Cases when diabetes was provoked by mutation in akt2 gene have been reported (4). GLUT4 translocation to plasmalemma 
caused by insulin is decline in hypertrophic adipocytes (7). Thus, sensitivity to insulin is diminished, fat storage is affected, the level of circulatory FAs is increased and dyslipidemia develops. Lipogenesis is inhibited by fasting and polyunsaturated fatty acids. Fasting causes the decrease of glucose level and increase of free fatty acids (FFA) level in blood. These changes are regulated by hormones which either inhibit (leptin) or enhance (angiotensin) lipogenesis.

Lipolysis is the process of digestion of triacylglycerol molecule to FFAs and glycerol. In the process of lipolysis, triacylglycerol molecule is hydrolyzed to FAs and glycerol. This process is catalyzed by two enzymes - hormone-sensitive lipase and monoacylglycerol lipase. Hormone-sensitive lipase is inhibited by insulin and activated in the presence of glucagon and epinephrine. Glycerol is transported to the liver, where it becomes involved in glycogenesis. FFAs outside adipocytes bind with albumin and are transferred to the liver, muscles and other tissues for further oxidation. Lipolysis is regulated by the insulin, catecholamines and natriuretic proteins (5).

Insulin is a pleiotropic hormone, the main function of which is the regulation of glucose homeostasis, as well as involvement in the regulation of protein synthesis, cellular growth and differentiation. Insulin release increases glucose uptake by muscles and adipose tissue, inhibits glucose production by liver and stimulates glucagon synthesis (6). It plays the central role in the development of hypertension, diabetes, and cardiometabolic syndrome (8). The main function of insulin is induction of glucose absorption in muscles and heart, and inhibition of the synthesis of glucose and very low-density lipoproteins (VLDL) in liver. Under fasting conditions insulin secretion is inhibited; glucose synthesis in the liver and kidneys ensues (gluconeogenesis), as well as glucagon transformation into glucose (glucanolysis). After meal, insulin is secreted, which inhibits gluconeogenesis and glucanolysis. Insulin receptors are found in several cell types. At molecular level, binding of insulin molecule with its receptor, which is comprised of two $\alpha$ and two $\beta$ subunits, activates tyrosine kinase activity of the receptor, leading to auto-phosphorylation of the receptor and formation of binding site with insulin receptor substrates, which are the main targets and signal transformers for insulin receptors (6).

\section{Adipose tissue endocrine functions}

WAT can be considered as the largest endocrine organ. It is capable of adipokines synthesizing: hormones, cytokines, growth factors, enzymes, complement factors and matrix proteins. Moreover, this tissue also expresses the receptors for the majority of the aforementioned molecules. Thus, fatty tissue is involved in immunity regulation, food intake regulation, energy metabolism, homeostasis and blood pressure homeostasis. Visceral adipose tissue has been proven to be more metabolically active than subcutaneous one. WAT is involved in metabolic processes via endocrine, paracrine, and autocrine regulation (9).

Disorders in synthesis of certain adipokines may be considered as the main reason of development of lifestyle-associated diseases such as T2D, atherosclerosis, hyperlipidemia and hypertension, which, in turn, are the constituents of metabolic syndrome. Consequently, the regulation of key adipokines is a promising method of metabolic syndrome treatment.

Leptin and adiponectin are the two main hormones regulating lipogenesis and lipolysis processes. In addition to them endocrine adipokines include angiotensin, acylation stimulating protein (ASP), 11 $\beta$-Hydroxysteroid dehydrogenase type 1 (11b-HSD1), adipose triglyceride lipase (ATGL), Comparative Gene Identification-58 (CGI-58), glycosylphosphatidylinositol anchored high density lipoprotein binding protein 1 (GPI-HBP1), hormonesensitive lipase, lipoprotein lipase, perilipin, sterol regulatory element-binding proteins (SREBPs) (7).

Leptin is a hormone synthesized by adipocytes, involved in lipid and glucose metabolism processes, energy release, regulation of pro-inflammatory response of T-lymphocytes and anti-inflammatory response of a link of congenital immune system. According to its structure and functions it belongs to a family of cytokines IL-6. Leptin accelerates locally the process of lipolysis and oxidation of fatty acids and also inhibits lipogenesis. The level of leptin in blood is higher in patients with obesity, and increases in case of diet with high caloric content. And, vice versa, leptin level is decreased under fasting conditions. Leptin concentration is declining in case of low insulin concentration. Leptin administration to patients with low leptin level results in abrupt reduc- 
tion of fat quantity and normalization of triglyceride and glucose level in blood (7).

Adiponectin is another key hormone, synthesized exclusively by adipose tissue; it is involved in lipid and glucose metabolism and it has immunological properties. It circulates as three isoforms - low-molecular-weight (LMW), mediummolecular-weight (MMW), and high-molecularweight (HMW). Decrease in HMW adiponectin level is associated with T2D. Decrease of adiponectin level results in reduction of the activity of lipoprotein lipase, which may increase triglyceride level, worsen VLDL catabolism and promote high-density lipoproteins (HDL) catabolism, which eventually results in increased secretion of FFAs by adipocytes (8). It is suggested to use this peculiarity as early diagnostics of the disease. Adiponectin has antiinflammatory and antitumor properties, improves sensitivity to insulin and stimulates oxidation of fatty acids and glucose uptake in skeletal muscles and adipocytes. In addition, it inhibits a cascade of inflammatory reactions, including $\mathrm{TNF} \alpha$ synthesis. This process is regulated by AMP-activated protein kinase (AMPK), responsible for glucose uptake by skeletal muscles (10).

Two types of adiponectin receptors are known - AdipoR1 and AdipoR2. AdipoR1 is localized in skeletal muscles; it stimulates AMPK and results in lipid oxidation. AdipoR2 is localized in the liver and increases sensitivity to insulin. Adiponectin stimulates appetite and reduces energy release. Adiponectin is regulated by catecholamines, growth hormones, insulin and glucocorticoids. Glucocorticoids decrease adiponectin level in blood and inhibit its expression.

Adipose tissue expresses all components of renin-angiotensin-aldosterone system (RAAS), including angiotensinogen (AGT), renin, angiotensinconverting enzyme and angiotensin II type 2 receptor. Moreover, the level of angiotensin mRNA and the protein itself in adipose tissue is regulated by nutrition. Fasting increases its level, while hypernutrition decreases it. Angiotensin II stimulates prostacyclin synthesis, differentiation of adipocytes and lipogenesis. Besides, it is known that angiotensin II influences cardiovascular processes, in particular, hypertension and hemostasis (9).

Acylation stimulating protein (ASP) is formed from three proteins of alternative complement pathway - C3, factor B and adipsin, which are synthesized by adipocytes. It enhances lipogenesis, performing GLUT4 translocation into glycerol-3- phosphate and increases the activity of diacylglycerol acyltransferase (DGAT) - an enzyme catalyzing synthesis of triglycerides. ASP increases insulin secretion and liporprotein lipase activity. ASP inhibits the activity of hormone-sensitive lipase. Such factors as obesity, T2D and cardiovascular diseases contribute to raising of ASP level, while physical exercise and weight loss decrease its level. The decline of ASP level in people over age was also found (10).

11b-HSD1 is type $11 \beta$-hydroxysteroid dehydrogenase, an enzyme synthesized in adipose and other tissues. Its function is in enhanced conversion of inactive circulatory cortisone into active cortisol. 11bHSD1 expression by adipocytes can be increased in case of excessive body weight (7). Excessive 11bHSD1 expression can accelerate the development of dyslipidemia via glucocorticoid lipolysis, enhanced via cortisol and decrease of lipoprotein lipase (LPL) activity in peripheral and subcutaneous fatty tissue, due to which excessive FFAs release is observed.

ATGL is adipose triglyceride lipase, the main enzyme of lipase class synthesized by adipocytes. Its activity is adjusted by regulatory proteins - perilipins. Studies on animal models have shown that ATGL is responsible for more than $95 \%$ of triglyceride hydrolysis in WAT. ATGL expression is decreased in case of obesity. ATGL function disorders affect catecholamine-induced lipolysis (7).

CGI-58 is a protein comparative gene identification-58, a hydrolytic protein enhancing ATGL activation. CGI-58 is activated via $\beta$-adrenergic stimulation of adipocytes. It is unknown whether its level is varied in obesity.

GPI-HBP1 is glycosylphosphatidylinositol anchored high density lipoprotein binding protein 1 which binds HDLs; this glycoprotein is necessary for lipolytic processing of triglyceride-rich lipoproteins and LPL transportation to capillary lumen. In case of people with excessive body weight, expression of this receptor in visceral adipose tissue is lower compared to subcutaneous ones (7).

Hormone-sensitive lipase (HSL) is the main enzyme of lipolysis and its concentration is decreased in case of hyperinsulinemia. Elevated insulin concentration after meal exerts negative effect on HSL regulation, decreasing intra-adipocytic and increasing extra-adipocytic lipolysis of triglycerides. This hypogenic activity leads to adipocyte enlargement; and, vice versa, fasting and insulin secretion drop activates HSL and, as a result, intensifies FFAs release from adipocytes. Decreased HSL activity can exert 
positive effect on dyslipidemia development. Thus, decreased FFAs release ensues, their uptake by the liver is slowing down, VLDL generation is lowering and HDL elimination period is decreasing (11).

Lipoprotein lipase is an enzyme secreted by adipose tissue and muscles. LPL interacts with triglyceride-rich lipoproteins, enhancing extraadipocytic intravascular lipolysis of triglycerides. Apolipoprotein CII enhances LPL-induced hydrolysis of triglycerides; apolipoprotein CIII inhibits LPLinduced hydrolysis of triglycerides. Under normal conditions, after meal, $85 \%$ of FFAs is transferred to adipocytes via the function of insulin, LPL and HSL (12).

Perilipin is an intra-adipocytic protein which binds lipid droplets. Perilipin protects against lipolytic activity of hormone-sensitive lipase. Perilipin level decrease stimulates enhanced lipolysis of triglycerides by HSL, which leads to increase of circulating FFAs concentration and dyslipidemia development.

SREBPs are transcription factors found not only in adipocytes but also in other tissues, which regulate intracellular content of lipids via the regulation of enzymes, involved in cholesterol synthesis.

The role of adipose tissue in immune system functioning

Insulin resistance pathogenesis studies have revealed that chronic adipose tissue inflammation is the cause of insulin resistance induced by obesity (13, 14). In obesity, besides the hypertrophy of adipocytes, the number of macrophages, infiltrating fatty tissue, is also increased.

Adipocyte tissue macrophages (ATM) are divided by the spectrum of activity into proinflammatory M1-cells and anti-inflammatory M2cells. M1 macrophages are activated according to the classical mechanism, while M2 macrophages are activated via an alternative pathway. In obesity, the number of pro-inflammatory macrophages substantially exceeds the number of anti-in-flammatory ones. Pro-inflammatory macrophages synthesize several cytokines - TNF $\alpha$, IL-1 $\beta$, IL-6, CRP (C-reactive protein), MCP-1. These cytokines affect the insulin signalling. The existence of directly proportional interrelation between the inflammation degree, adipokine secretion and development of insulin resistance has been proven (6). The full range of the major adipokines is shown in Table 1.

$\mathrm{TNF} \alpha$ has become the first molecule related to obesity, inflammation and T2D. TNF $\alpha$ is a transmembrane protein, synthesized in the size 26 $\mathrm{kDa}$ and cleaved by metalloprotease to $17 \mathrm{kDa}$ to the soluble TNF $\alpha$. The local macrophages are the main source of TNF $\alpha$ in adipose tissue. TNF $\alpha$ increases lipolysis rate and prevents lipogenesis. In hypothalamus, TNF $\alpha$ decreases the appetite and stimulates synthesis of hormone corticotropin. In liver, it inhibits expression of genes responsible for oxidation of fatty acids and stimulates expression of genes responsible for fatty acids synthesis. TNF $\alpha$ is an attractant for other immune cells, and thus it increases inflammation (7).

Table 1. Bioactive substances produced by adipose tissue and affecting immunological processes in humans (7)

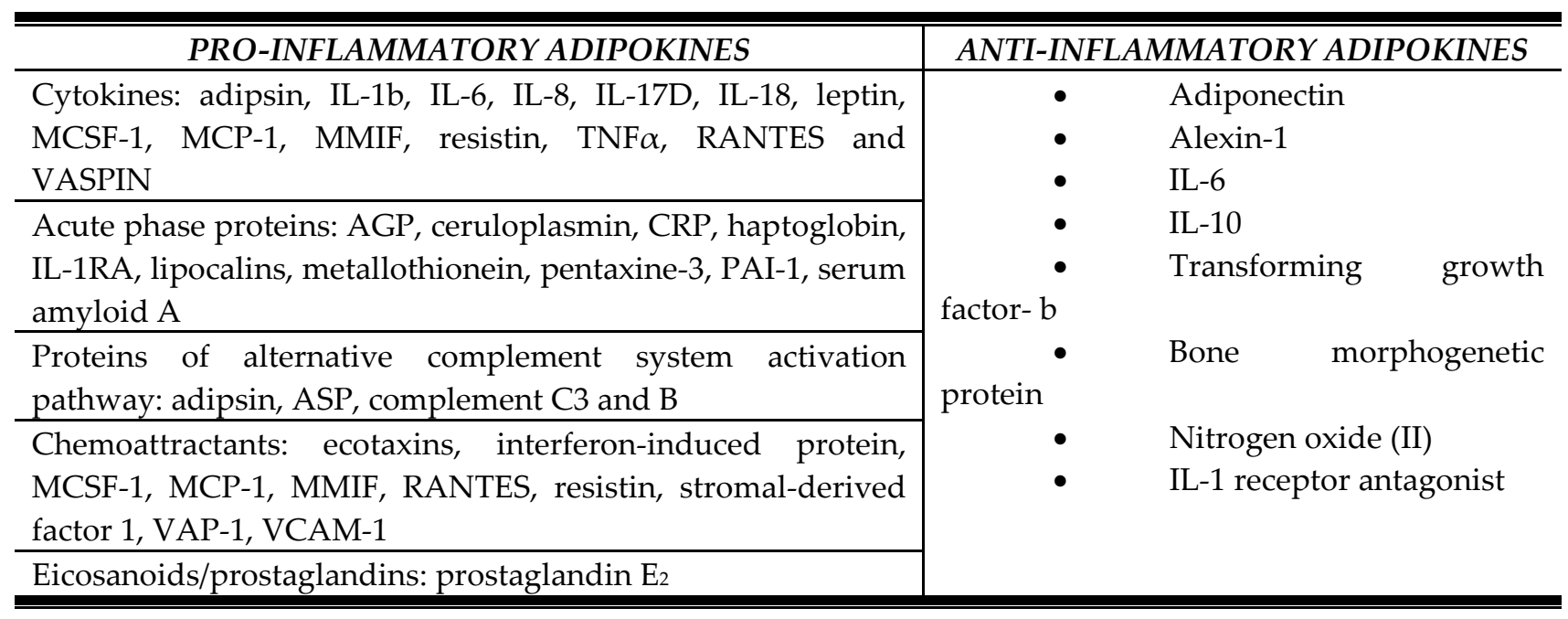


Studies (15) have shown that TNF $\alpha$ mRNA expression level considerably affects insulin signalling disorders. Moreover, it has been experimentally proven that long-term $\mathrm{TNF} \alpha$ administration decreased sensitivity to insulin in animals. At the same time, deletion of $\mathrm{TNF} \alpha$ or its receptors improves glucose uptake and sensitivity to insulin in rats, though TNF $\alpha$ neutralization did not restore insulin sensitivity in diabetic patients.

Mechanism of insulin sensitivity deterioration includes inhibition of signal capability of insulin receptor substrate via activation of serine kinase cJun N-terminal kinase (JNK) or NF- $\kappa B$ kinase inhibitor and via increased suppressing of cytokine signalling-3 r (SOCS3) expression. SOCS3 impede insulin sensitivity by preventing the activation of insulin receptors, receptors of insulin substrate or by ruining them (15-17).

In hepatocytes, TNF $\alpha$ impede FAs oxidation via the induction of protein phosphatase $2 \mathrm{C}$ and AMPK suppression. Decrease of FAs oxidation intensity is associated with growth of accumulation of bioactive lipids, e.g. diacylglycerol, which activates protein kinase $C$ and inhibits the functions of the receptors of insulin substrate. Moreover, there is a hypothesis suggesting that hypertrophic adipocytes are capable of releasing saturated FAs as an endogenous alarm signal (9).

The role of IL-6 in metabolic syndrome (MS) development began to be considered relatively recently (6). Notice that IL-6 is responsible for differentiation and maturation of blood cells and inflammation in tissue damage sites. It is synthesized by adipocytes, immune cells, and muscles. Its molecular weight varies from 21 to $28 \mathrm{kDa}$. In the human organism, $30 \%$ of circulatory IL-6 is released by cells of visceral adipose tissue. IL-6 level is increased in case of obesity via TNF $\alpha$ and IL-1. In T2D patients, IL-6 level is increased proportionally to the body mass index and concentration of FFAs in plasma. IL-6 affects insulin signalling via decreased expression of IRS and GLUT4 genes (6), as well as via induction of SOCS3 expression, which damages insulin receptors, and via IRS-1 phosphorylation in adipocytes and hepatocytes (9). In addition, IL-6 influences negatively the expression of adiponectin (6).

At the same time, the role of IL-6 in provoking obesity and T2D is controversial. Thus, it was demonstrated that in mice with genetic IL-6 deletion the process of FAs oxidation was deviated and diabetes and obesity developed in 9 months. The experiment with IL-6 administration has shown that it increases glucose uptake via AMPK activation. Nevertheless, it also caused phosphorylation of JNK1/2, p38MAPK and ERK1/2 (10), which affected the interaction between IS and IRS. As a result, it has been concluded that short-term IL-6 administration provoked improved glucose uptake, while its longterm, chronic effects caused insulin resistance (10).

C-reactive protein (CRP) is an acute phase protein, serving as a marker of visceral inflammation. CRP secretion is increased as a result of IL-6 and $\mathrm{TNF} \alpha$ secretion.

MCP-1 is monocyte chemoattractant protein, released by endothelial cells and macrophages. It has been shown in studies that increased MCP-1 expression plays an important role in insulin resistance pathogenesis, while the number of macrophages in adipose tissue is directly dependent on MCP-1 expression (18).

Resistin is a small protein (125 kDa), which contains high amounts of cysteine. It is synthesized by adipocytes and other cell types. Resistin circulation is elevated in people and mice with obesity. Use of anti-resistin monoclonal antibodies had positive effect on normalization of blood glucose level and insulin sensitivity in mice. Macrophage stimulation by a lipopolysaccharide or anti-inflammatory cytokines results in increased resistin secretion. It is interesting that resistin secretion by pre-adipocytes is 3 times higher than in mature adipocytes, which is indicative of the fact that resistin regulates adipogenesis. Resistin stimulates endothelial cells to secrete MCP-1, vascular cell adhesion molecule 1 (VCAM-1), inter-cellular adhesion molecule 1 (ICAM-1), which are adiponectin antagonists (9).

Plasminogen activator inhibitor-1 (PAI-1) is a single-chain glycoprotein with $45 \mathrm{kDa}$ of molecular weight. Obviously, the amount of PAI-1 secreted by adipocytes is proportional to the total mass of adipose tissue. Visceral adipose tissue generates more PAI-1 than subcutaneous one. PAI-1 synthesis is positively regulated by insulin, glucocorticosteroids, angiotensin II, some fatty acids and most of all by cytokines (TNF $\alpha$ and growth factor- $\beta$ ), and is negatively regulated by catecholamines (9). 


\section{The role of obesity in the development of insulin resistance and diabetes mellitus type 2}

Metabolic syndrome (MS) is interpreted as a group of metabolic disorders associated with development of cardiovascular diseases, T2D, and atherosclerosis. MS is characterized by a combination of certain metabolic disorders such as dyslipidemia, elevated blood pressure, increased glucose level and prothrombotic condition $(19,20)$. Insulin resistance can be the key state leading to MS. IR increases the risk of development of T2D, cardiovascular diseases and atherosclerosis. Obesity with its metabolic complications is recognized as global epidemics. $75 \%$ of adult population of the USA suffers from obesity or overweight. Various consequences of excessive fat accumulation are associated with affected structure and functional activity of adipose tissue, which, in its turn, is one of the key reasons of IR development (7).

At present, obesity is characterized as a condition of systemic chronic inflammation (low grade inflammation) (5). It is known, that inflammation is a protective body response to infection or tissue damage and under normal conditions, acute inflammation phase is followed by recovery of body. Nevertheless, certain factors can affect the protective activity of body systems. For example, chronic lowgrade inflammation associated with oxidative stress is a typical feature of obesity, insulin resistance, and diabetes mellitus. There is no doubt that obesity exerts substantial effect on adipokine synthesis, sensitivity to insulin and development of T2D (6).

Diabetes is a metabolic disorder characterized by elevated glucose level and deficiency of insulin or affection of its effects. T2D is usually characterized by normal insulin production by pancreatic cells, but an impaired sensitivity of the target receptors to insulin. Genetic predisposition, obesity, sedentary lifestyle and ageing are the factors provoking IR development (2). IR affects functioning of insulindependent tissues such as adipose tissue, liver and skeletal muscles.

At present, much attention is paid to dyslipidemia and inflammation processes as the main mechanisms of IR development. Majority of scientists agree that the mechanism underlying insulin signaling disorders is activation of stress kinases (ERK, JNK, IKK, S6K1), which causes IRS phosphorylation and, as a consequence, prevents its binding with insulin receptor. The primary cause of activation of stress kinases remains unknown. The main reasons stated are excessive energy, effects of saturated fatty acids and lipid oxidation. Obesity is characterized by growth of fatty tissue with increase of adipocytes' size. Hypertrophy of adipocytes causes dysfunction of organelles (especially mitochondria and endoplasmic reticulum), endocrine regulation and lipid deposition disorders, increased FFAs circulation and lipotoxic damages of nonadipocyte containing tissues such as liver and muscles (7). Besides, excessive fat content is associated with higher rate of formation of reactive oxygen species, oxidative stress and chronic inflammation.

Adipose tissue plays the central role in IR etiology and pathogenesis of T2D (21). Excessive lipolysis is observed in obesity, and it is closely associated with IR. Fatty tissue of overweight people is characterized by the presence of high numbers of pro-inflammatory macrophages releasing cytokines (TNFa, IL-1b, IL-6). This causes the development of inflammation. These cytokines can directly inhibit the effect of insulin via paracrine regulation, e.g. by decreasing adiponectin concentration (13). Cytokines stimulate stress kinases $\mathrm{S} 6 \mathrm{~K}, \mathrm{IKKb}$, JNK1, PKCF, which phosphorylate IRS-1 or inhibit serine residues, affecting insulin signaling. Cytokines also affect IR via transcription mechanisms by decreasing the expression level of the main molecules regulating insulin signaling.

It has been established that raised level of formation of reactive oxygen species (ROS) in adipocytes also provokes IR development. The excess of FFAs causes the dysfunction of mitochondria and NF-kB activation, which provokes increased formation of ROS. Such cytokines as TNFa and IL-6 release nitric oxide synthase (NOS), which catalyzes the release of nitric oxide (19). Lipid peroxidation is the process of oxidation of polyunsaturated fatty acids. Lipid peroxidation causes damage of membrane proteins. Oxidized LDLs are capable of avoiding scavenger receptors and return into blood flow (22). The causes of IR can include elevated phosphatase expression and negative regulation of protein kinase reactions cascade (8).

Complex relationship between obesity, increased circulating FFAs level, oxidative stress, inflammation, glucose transport and utilization disorders is schematically shown in Figure 1. 


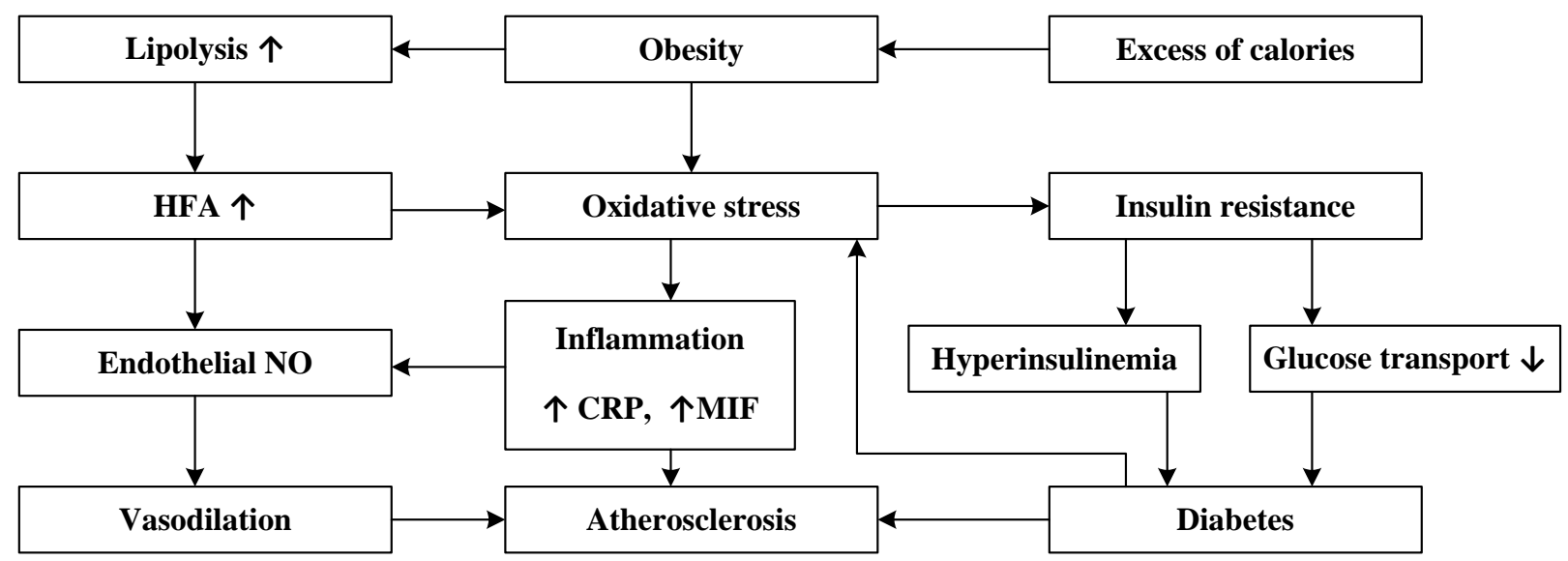

Figure 1. Relationship between lifestyle, oxidative stress, insulin resistance, inflammation and atherosclerosis (23)

Dyslipidemia effect on the development of insulin resistance and metabolic syndrome

Dyslipidemia is another mechanism of development or consequence of IR (13). It is the condition characterized by elevated level of triglycerides, LDL and decreased level of HDL $(24,25)$. Hypertrophy of adipocytes results in affection of endocrine and immune functions of adipose tissue, the outcome of which is dyslipidemia (7).

Cholesterol, triglycerides and lipoproteins are normally contained in blood plasma. All blood plasma cholesterol is divided into the three main classes: very low-density lipoproteins (VLDL), lowdensity lipoproteins (LDL), high-density lipoproteins (HDL). There are also two minor classes - intermediate-density lipoproteins (IDL) and lipoprotein (a) $[\mathrm{Lp}(\mathrm{a})] .70 \%$ of blood plasma cholesterol is represented by LDL - the main atherogenic lipoprotein (24).

The surface of lipoproteins contains apolipoproteins, which perform transport and regulatory function. Apolipoprotein B100 is necessary for formation of VLDL, IDL, LDL. Apolipoprotein AI is essential for HDL formation.

Deviations in the ratio of these lipoproteins occur due to excessive content of FFAs, which, in its turn, causes oversynthesis of triglycerides in liver. FFAs excess increases accumulation of triglycerides. Elevated blood triglyceride level is one of the risk factors of atherosclerosis and T2D development. It is known, that triglycerides in the blood flow are the form of FAs transport. Triglycerides are secreted into blood by liver in the form of VLDL. VLDL serves not only for further release of FFAs, which, as well as glucose, is consumed by cells as energy substrate, but also for cholesterol transport. It has also been shown that insulin resistance occurs due to accumulation of triglycerides in cells of non-fatty tissues, mainly in skeletal muscles and liver (11). Re-synthesis of triglycerides occurs in liver and these triglycerides bind with apoB-100 protein and secrete into blood. Such indirect FAs transport pathway "adipose tissue - liver - blood" was created evolutionary for realization of complicated mechanisms of metabolism of fatty acids as energy substrates and cholesterol as a substrate for synthesis of sex hormones and bile. Triglycerides decrease HDL concentration and stimulate generation of small LDL particles from VLDL (8).

LDL particles differ in size, density, and lipid composition. Large and middle-sized LDL particles are present in blood of healthy people. At the same time, small LDL particles are more atherogenic. They decline receptor ability to bind, penetrate better through endothelium, and are more prone to oxidation (26). Their formation happens via VLDL formation in liver before formation of IDL, and subsequently LDL as a result of lipolysis (Figure 2).

Increased FFAs uptake by liver causes hepatosteatosis (non-alcoholic fatty liver disease). Due to enhanced FFAs uptake by liver, synthesis of VLDLrich triglycerides is increased. Having reached the blood, VLDL affect enzymatic metabolism with other particles of HDL and LDL lipoproteins via interaction with cholesteryl ester transfer protein (CETP). They can get smaller and attain atherogenic properties via interaction of these particles with lipases (7). Insulin 


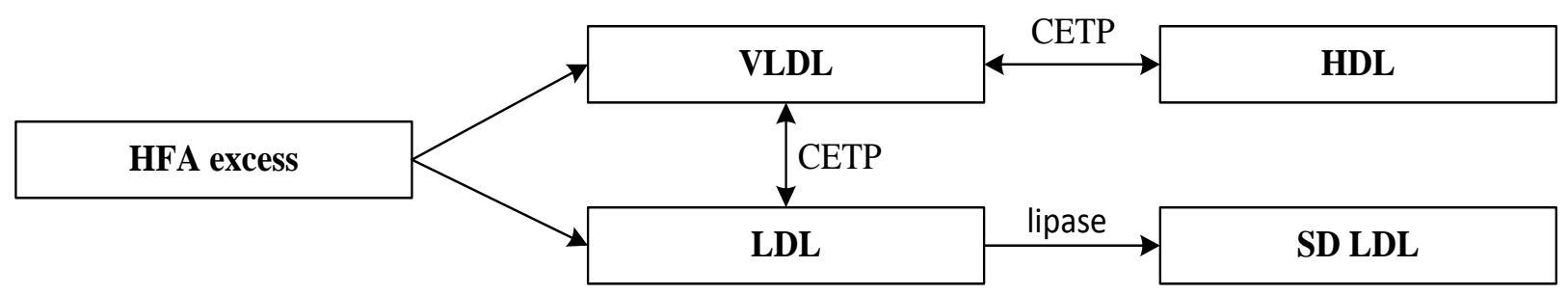

Figure 2. Simplified scheme of dyslipidemia development in insulin resistance $(7,19)$

resistance in liver develops according to this mechanism.

Dyslipidemia is a complication which, in most cases, accompanies IR. The danger of this phenomenon lies in the formation of atherogenic cholesterol. Not all FFAs influence biological processes in a similar way. Division of FAs into saturated and unsaturated ones by nature of chemical composition has been accepted. Their biological functions depend on their composition.

Saturated fatty acids are fatty acids lacking unsaturated (including double) bonds in carbon backbone chain. Under the conditions of obesity, IR, and elevated level of circulatory FFAs, immune cells exist in the medium with excess of lipids. Numerous studies have shown that the effect of saturated FAs on various cell types causes activation of inflammatory processes in macrophages, adipocytes, hepatocytes, and myocytes. Saturated FAs are known as bacterial endotoxin components. That is why the immune system recognizes saturated FAs as bacterial components. This occurs due to the activation of $\mathrm{IKKb} / \mathrm{NFkB}$ and JNK1/AP1 and cytokine release (13). Several independent laboratories announced that inflammatory effects of saturated FAs are associated with interaction with Tlr4 and/or Tlr2. Tlr2, Tlr4 are included to $\mathrm{Tlr}$ receptor family which recognize pathogen-associated molecular patterns (PAMP) and endogenous indicators of tissue damage. Tlr4 ligand is lipopolysaccharide, an ingredient of gram-negative bacteria, and Tlr2 ligand is lipotheichoid acid, a component of gram-positive bacteria. In case of the absence of Tlr4, saturated FAs do not initiate a cascade of inflammatory signals. Moreover, in mice with genetic Tlr4 deletion sensitivity to insulin does not develop at high-fat diet (HFD) feeding.

It is doubted whether saturated FAs are a direct ligand to Tlr4. Nevertheless, there are several assumptions on how saturate FAs can stimulate Tlr4 in an indirect manner. One of the options is interaction via proteins, binding saturated FAs and acting as Tlr4 co-receptors. Saturated FAs induce Tlr4dependent gene expression via Tlr4 dimerization, necessary for receptor activation, with specialized lipid domains - lipid rafts. It depends on the ability of saturated FAs to stimulate NADPH by ROS oxidase. Another hypothesis states that administration of saturated FAs results in membrane re-distribution of tyrosine kinase c-Src, thus, it is concentrated in lipid rafts with further activation. Due to this, activation of JNK1 and its pro-inflammatory target genes takes place. For example, cultivation of macrophage line with palmitic and lauric acids promotes JNK1 phosphorylation, which causes increased expression of pro-inflammatory cytokines (27-30). The third possible option of the effect of saturated FAs on inflammation development can be the fact that saturated FAs stimulate synthesis and release of endogenous signals from damaged tissues, recognized by Tlr.

Moreover, saturated FAs can influence inflammation via mechanisms not related to Tlr. Administration of saturated FAs results in increased formation of ROS by them, which activates several stress kinases. Studies have shown that elevated ROS level provokes activation of inflammasome complex NLRP3-ASC, which results in elevated IL-1b level. In addition, saturated FAs are precursors of diacylglycerols, which also impede sensitivity to insulin (27).

Saturated FAs are also precursors of ceramide synthesis, which directly decreases insulin signaling (13). Many authors mention convincing dependence between cellular ceramide concentration and IR development. Saturated FAs, interacting with Tlr4, initiate the cascade of enzymes involved in ceramide synthesis. It is interesting that $\mathrm{TNF} \alpha$ stimulation also 
increases ceramide synthesis, and these mechanisms are IKKb-dependent.

Polyunsaturated fatty acids. Unsaturated FAs are fatty acids which have at least one double bond in fatty acid chain. FA is monounsaturated if its chain contains at least one double bond and polyunsaturated if it contains more than one double bond Thus, n- 6 unsaturated FAs have the first double bond next to the sixth carbon atom, calculated from methyl residue.

Recently, scientists have started discussing the interrelation between the state of adipocyte membrane and IR mainly due to its effect on IRS and GLUT4. There are some data that fatty acid composition of phospholipids of macrophage membrane can affect the inflammation process in several ways. Membrane physical properties, such as fluidity and formation of lipid rafts, depend on specific properties of FAs of membrane phospholipids and modify the cascade of reactions, regulated via the membrane. Phosphocholine and phosphoethanolamine are the main two phospholipid classes of human blood plasma. They are concentrated in macrophage membrane, and also represent the main phospholipids of erythrocytes. Besides, fatty acid composition of erythrocytes affects the immune system function as the arachidonic acid and is a substrate for synthesis of bioactive mediators - eicosanoids. Arachidonic acid deficiency results in eicosanoid synthesis disorders and, as a result, disorders of immune and inflammatory reactions. Thus, phosphocholine and phosphoethanolamine are the main depots of omega-3 FAs and omega-6 FAs in cells and fluids involved in inflammation development (27).

Eicosanoids regulate the intensity and duration of inflammation (Figure 3). Prostaglandins are a group of eicosanoids formed from arachidonic acid as affected by consecutive actions of two enzymes phospholipase A and cyclooxygenase. Both enzymes are controlled via signaling pathways which are sensitive to cytokines and pathogen-associated molecular pattern (PAMP), which causes rapid increase of prostaglandin synthesis. As a consequence, prostaglandin metabolites have different inflammatory effects (13). Among eicosanoids, the ones with best studied functions are prostaglandin E2 (PGE2) and leukotriene B4 (LTB4). PGE2 has several antiinflammatory functions - it suppresses proliferation of lymphocytes, activity of natural killers (NK) and synthesis of TNF $\alpha$, IL-1, IL-6, IL-2, interferon gamma $(\mathrm{IFN} \gamma)$.

LTB4 enhances vascular permeability, local blood flow, acts as a potent chemotactic agent for leukocytes, causes release of lysosomal enzymes, formation of ROSs, inhibits proliferation of lym-

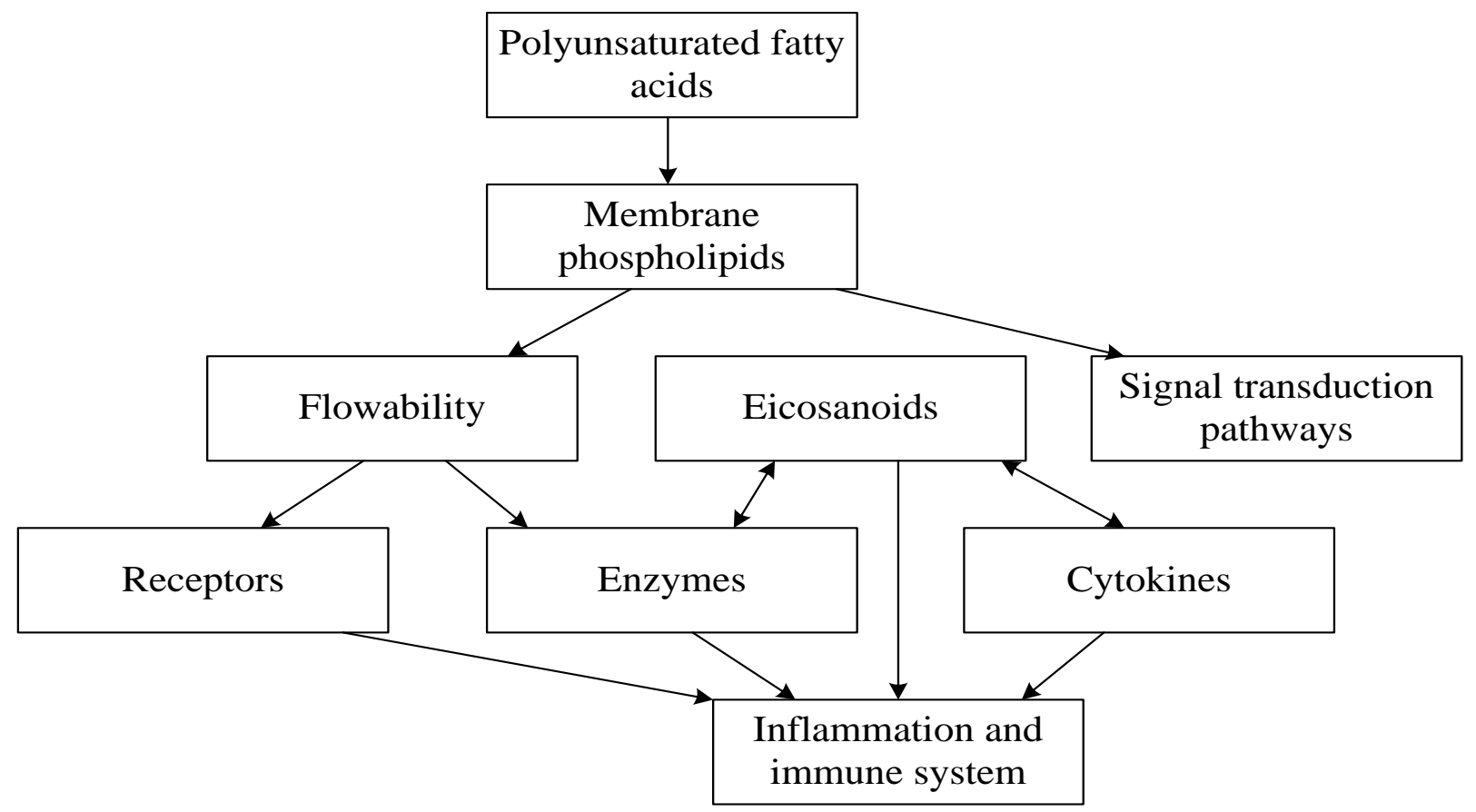

Figure 3. Interrelation between saturated fatty acids and immune system functions (23) 
phocytes and improves NK activity. Moreover, it is involved in the regulation of cytokine functions and enhances synthesis of TNF $\alpha$, IL-1, IL-6, IL2, IFN $\gamma$ (23).

A large number of cellular signal molecules is generated from membrane phospholipids (ceramides) and various types of phospholipids and mediators of phospholipid origin carry out regulation of the functions of certain proteins involved in inflammatory processes. Changes of phospholipids' fatty acid composition affects the affinity of the substrate for enzymes involved in synthesis of signal molecules, essential for coordinated work of the immune system (23).

Polyunsaturated FAs of phospholipids are capable of regulating inflammation via their role in membrane fluidity, formation of lipid rafts and receptor functions. Many lipid mediators, synthesized from omega-6 FAs, have pro-inflammatory properties. If their quantity is excessive, they are responsible for inflammation development. At the same time, the key omega-3 FAs docosahexaenoic (DHA) and eicosapentaenoic (EPA), are components of anti-inflammatory mediators, and that explains their positive effect on the organism. It has been shown that enrichment of the diet with omega-3 FAs reduces TNF $\alpha$ expression.

The mechanism of this effect becomes more and more clear. There is a lipid class interacting with G-protein-coupled receptors (GPCRs), including GPR40, 41, 43, 84, and 120. GPCRs are a family of transmembrane receptors including catecholamine receptors, $\beta-\mathrm{AR}$ and $\alpha 2-\mathrm{AR}$, regulating lipolysis (5). Recent studies have indicated that omega- 3 fatty acids are capable of stimulating GPR120. It is important that the use of TNF $\alpha$ agonists does not interupt inflammation development, while omega-3 fatty acids decrease pro-inflammatory activity of macrophages. At the same time, no omega-3 anti-inflammatory effect is observed in case of GPR120 absence; thus, it is obvious that omega-3 FAs is GPR120 ligand and realizes anti-inflammatory effect via this receptor (13).

The mechanism of this phenomenon is that transforming growth factor's beta-activated kinase 1 (TAK1) is a proximal kinase in these proinflammatory pathways. In response to inflammation signals, adaptor protein TAB1 interacts with TAK1 and activates it. Thus, stimulation of both IKKb/NFkB and JNK/AP1 pathways takes place. GPR120 activation by omega-3 FAs specifically inhibits TAK phosphorylation and activation, assuring Tlr and
$\mathrm{TNF} \alpha$ inhibition mechanism. $\beta$-arrestins are a family of molecules which can serve as adaptors or scaffold proteins for different GPCR. Omega-3 FAs stimulation leads to direct interaction between GPR120 and $\beta$-arrestin-2. At the same time, antiinflammatory effect of GPCR is, without a doubt, $\beta$ arrestin-2-dependent. The mechanism of this lies in the fact that DNA stimulation increases GPR120/ $\beta$ arrestin-2 interaction with following internalization of the complex. Internalized $\beta$-arrestin- 2 associates with $\mathrm{TAB} 1$, preventing the interaction between TAB1 and TAK1, resulting in TAK1 activation with the following inhibition of descending $\mathrm{IKKb} / \mathrm{NFkB}$ and JNK/AP1 inflammatory signal (13).

\section{Promising approaches in therapy of metabolic syndrome}

At present, three independent classes of targets are classified in adipose tissue, suitable for therapy of obesity and diabetes melitus: adipokines, hormonal sensitivity mediators, and enzymes involved in lipid storage.

Modulators of hormone activity are already approved as the main therapeutic target for peroxisome proliferator-activated receptors (PPARs) agonists, a class of antidiabetic medications increasing sensitivity to insulin (31). Thiazolidinediones (TZDs) are synthetic agonists of PPAR $\gamma$ receptors. At the same time, the use of TZDs has several side effects.

At present, improvement of efficacy of new medicinal products is conducted in two directions: ligands having more complete effect on PPAR $\gamma$ or agents stimulating PPAR $\gamma /$ RXR heterodimer via other ways. Obtaining of all possible information on components of PPAR $\gamma$ signaling system (endogenous ligands and enzymes, levels and modification of receptors, co-activators and co-repressors, transcription targets) would provide better understanding of the mechanisms of diabetes and obesity development.

PPARs as the main therapeutic target. PPARs belong to superfamily of nuclear hormonal receptors. These receptors perform the regulation of a large number of biological processes in the organism via control of gene expression. PPARs play the key role in the processes of energy storage and catabolism via several metabolic pathways, including FA oxidation and lipogenesis. Besides, they play an essential role in glucose metabolism, metabolic control, and immune 
response processes. That is why PPARs are viewed as targets for treatment of metabolic disorders and chronic inflammatory diseases (4).

Three PPAR types have been identified in mammals - PPAR $\alpha$ (NR1C1), PPARd/ $\beta$ (NR1C2), PPAR $\gamma$ (NR1C3) (32). Expression of these receptors in adults is tissue-specific. There are two variants of $\operatorname{PPAR} \gamma$ receptors - PPAR $\gamma 1$ and PPAR $\gamma 2$. It is important to note that PPAR $\gamma 2$ is expressed only by adipocytes; it is the main regulator of adipogenesis. It is also known that PPAR $\gamma$ triggers macrophage differentiation via alternative (pro-inflammatory, M2) or conventional (anti-inflammatory, M1) pathway (33). PPAR $\gamma$ expression is a necessary and sufficient prerequisite for differentiation of fibroblasts into adipocytes.

Due to transcriptional actions, immature adipocytes start accumulating lipid droplets and express late differentiation markers, e.g. C/EBP $\alpha$, GLUT-4, perilipin, as well as lipogenic and lipolytic enzymes. Besides, mature adipocytes are characterized by expression and secretion of highly specific and very late differentiation markers such as leptin, adiponectin, resistin, visfatin, omentin and adipsin. These molecules not only regulate energy exchange, metabolism of glucose and lipoproteins, but also serve as pro- and anti-inflammatory mediators of adipose tissue. Thus, adiponectin and collagenous repeat containing sequence of $26-\mathrm{kDa}$ protein (CORS-26) are anti-inflammatory, while resistin and leptin belong to pro-inflammatory adipocytokines $(34,35)$.

After heterodimerization with retinoid $X$ receptor (RXR), PPAR $\gamma$ are activated by binding with ligand. The latter is necessary for functioning of the former. These ligands are called insulin sensitizers; the best studied of them are glitazones or thiazolidinediones (TZD) - synthetic analogues of PPAR $\gamma$ ligand, widely used in MS therapy (4). Besides, endogenous substances have been identified recently, which can be PPAR $\gamma$ ligands and, among others, they may be represented by polyunsaturated FAs and their derivatives, e.g. 15-deoxy- $\Delta 12,14-$ prostaglandin J2 (36). Following activation with a ligand, PPAR $\gamma$ changes its conformation, which causes release of co-repressors and co-activators required for gene transcription.

PPAR $\alpha$ activators cause the decrease in plasma triglyceride levels, increase of HDL concentration associated with increased FAs uptake. They also improve the overall lipid homeostasis, protecting against lipotoxic damages associated with insulin resistance. PPAR $\gamma$ activation decreases secretion of pro-inflammatory cytokines and increases adiponectin plasma concentration. It has been established that PPAR $\alpha$ can reduce GLUT4 expression, thus decreasing glucose consumption $(37,38)$.

Synthetic PPAR $\gamma$ ligands. Thiazolidinediones are synthetic ligands and full PPAR $\gamma$ agonists. Their use is characterized by effective decrease of blood glucose concentration and improvement of sensitivity to insulin. One study has shown that TZD administration to rats increases the number of adipocytes and reduces their size (34). Despite this fact, the use of TZD has several side effects such as fluid retention, body weight gain, cardiac hypertrophy, bone fragility, and hepatotoxicity (39). For example, rosiglitazone was prohibited in Europe due to the high risk of cardiovascular diseases.

Increased activity and decreased quantity of PPAR $\gamma$ is considered to increase the improvement of sensitivity to insulin. This stipulates the interest to development of PPAR selective modulators, their components acting as partial agonists or antagonists to PPAR. Selective action of moderate PPAR agonists (SPPAR $\gamma \mathrm{Ms}$ ) depends on various structural changes occurring in ligand and receptor binding site. These changes are capable of influencing activation or repression of specific groups of target genes in various tissues (39).

Another approach to prevention of body weight gain associated with intake of full PPAR $\gamma$ agonists lies in developing of agonists, the effect of which covers two or all three PPAR isoforms. According to the hypothesis, PPAR $\alpha$ and/or PPAR $\delta$ stimulation activates oxidation of fatty acids and eliminates adipogenic effect of PPAR $\gamma$ agonism (40).

First type angiotensin II receptor (ATR1) blockers (sartans) can neutralize the effect of PPAR $\gamma$ activation on weight gain and at the same time preserve the positive metabolic effect.

Further progress in identification of these components promotes creation of more effective therapy for patient suffering from diabetes and elimination of side effects of available pharmacological products, for which PPAR $\gamma$ is a target, with maintenance of underlying metabolic activity.

Endocannabinoid substances. Recently, endocannabinoid system, metabolic disorders and obesity are related more and more frequently. Endocannabinoid system is a neurochemical system directly involved in physiological body restoration 
after a stress. There are two types of cannabinoid receptors - CB1 and CB2. Two ligands to CB1 receptor have been described - anandamide and 2arachidonoyl glycerol (2-AG), which simulate pharmacological activity of $\Delta 9$-tetrahydrocannabinol, active ingredient of cannabis. Cannabinoids have been proven to possess psychotropic effect, thus helping the body to fight stress (37).

$\mathrm{N}$-acetylethanolamines (NAEs) are a class of minor lipids, fatty acid derivatives, included in the composition of endogenous cannabinoid body system (27). Representatives of this class have a broad spectrum of biological activity; in particular, antiinflammatory, antioxidant, membrane stabilizing, immunomodulatory, neuroprotective, and adaptogenic action (22). They are divided into saturated (Nacylethanolamine, N-oleoylethanolamine) and unsaturated - (anandamide, 2-arachidonoyl glycerol, and N-palmitoyl-ethanolamine).

Unsaturated NAEs - arachidonoyl ethanolamide (NAE 20:4, "anandamide") and 2-arachidonoyl glycerol are the main endocannabinoids, exhibiting high biological and pharmacological activity, capable of modulating immune functions in people and animals, and also exerting anti-inflammatory and analgesic action. NAEs with saturated carbohydrate chain (e.g. NAE 18:0 N-stearoylethanolamine), though they do not bind CB1 and CB2-receptors, are formed, metabolized, and act together with other endocannabinoids. NAEs are found in mammal tissues under physiological conditions only in minor amounts (about $10-15 \mathrm{~mol} / \mathrm{g}$ ). Nevertheless, in various pathological processes, the content of these minor lipids can increase substantially. They have pronounced biological activity in concentrations $10^{-5}$ $10^{-9} \mathrm{M}(41,42)$.

Saturated NAEs are studied much less than unsaturated ones. It has been established that saturated NAEs cause addiction (43). It has recently been revealed that certain saturated and unsaturated NAEs are capable of binding PPARs. Some biological processes of NAEs are proven to be mediated via activation of various PPAR subtypes (10).

Besides well-studied endocannabinoids such as anandamide, there are substances, the role of which has just begun to be actively investigated. These include N-stearoylethanolamine (NSE). NSE level in brain of humans and rats is about $11-14 \%$ of the total quantity of endocannabinoids, while anandamide content does not exceed 7-8\%. NSE has several characteristics which make it resemble cannabinoids, but it does not bind with cannabinoid receptors (37). The interest of scientists to NSE is due to the fact that its membrane stabilizing, antioxidant and antiinflammatory properties have already been proven in many experimental studies.

Recent studies have shown that NSE is capable of activating lipid metabolism by in-building into lipid rafts and activating PPAR $\alpha$. It has been suggested that activation of GPR119 causes replication and increase in $\beta$-cell mass, and therefore their regeneration (25). Moreover, increased expression of PPAR $\alpha$ and PPAR $\gamma$ is capable of increasing sensitivity to insulin, normalizing lipid composition and exerting antioxidant properties. They are known to regulate energy metabolism via interaction with nuclear (PPAR $\alpha$ ) and GPR receptors.

At present, search for bioactive substances, capable of exerting compensatory and adaptogenic action in type 2 diabetes, is rather urgent. Minor signal lipids NAE are distinguished among such compounds. The capability of saturated NSE to normalize the content of main phospholipids and to compensate FAs imbalance in cellular content in several pathologies, thus manifesting membranestabilizing and membrane-protective properties, was demonstrated in series of research works $(6,23)$.

\section{CONCLUSIONS}

Two types of adipose tissue are found in human body - white and brown. These adipose tissue types differ in structure and, consequently, in functions. The main fatty tissue function is energy storage via the maintenance of balance between lipolysis and lipogenesis processes. Triacylglycerides synthesis process requires mandatory release and effect of insulin. Inhibition of lipogenesis and acceleration of lipolysis are observed in metabolic disorders, in particular, insulin resistance. These processes cause the excess of circulatory free fatty acids. Adipose tissue functioning is regulated by adipokines, excreted by it; the ones positively influencing lipogenesis and having anti-inflammatory properties are adiponectin, perilipin and acylation-stimulating-protein. The ones influencing lipogenesis and increasing FAs release negatively are leptin, 11b-HSD1, ATGL, CGI-58, HSL, LPL and SREBPs.

Inflammation condition is an essential part and one of the reasons of insulin resistance status. Inflammation degree depends on the ratio between 
pro-inflammatory and anti-inflammatory cytokines. Insulin signaling disorders caused by $\mathrm{TNF} \alpha$ are associated with AMPK inhibition and affecting of IRS phosphorylation. IL-6 affects insulin signaling via decreased expression of IRS and GLUT4 genes, induction of SOCS3 expression, negative effect on adiponectin expression, though complete IL-6 elimination results in diabetes mellitus and obesity. Neutralization of the main inflammation cytokines does not restore sensitivity to insulin, which is indicative of the fact that inflammation condition is not the only cause of IR.

Obesity provokes hypertrophy of adipocytes, increased formation of reactive oxygen species, oxidative stress and increased number of macrophages, releasing pro-inflammatory cytokines. Chronic low-grade inflammation develops due to obesity. Pro-inflammatory cytokines affect insulin signaling via stimulation of stress kinases.

Saturated FAs are immunogens; interacting with Toll-like receptors, they initiate a cascade of inflammatory reactions. Besides, metabolism of saturated FAs results in formation of ROS, which activates stress kinases. In addition, saturated FAs are a substrate for ceramide synthesis, which directly inhibits insulin signal.

The functions of signal and immune cells are dependent on phospholipid composition. Unsaturated FAs are a substrate for synthesis of bioactive mediators - eicosanoids. The ratio between proinflammatory and anti-inflammatory eicosanoids depends on the ratio between omega- 6 and omega- 3
FAs. Additionally, the membrane functioning is directly influenced by membrane physical properties such as fluidity and formation of lipid rafts. It should also be mentioned that mediators of phospholipid origin perform regulatory function in terms of work of certain proteins, involved in inflammatory processes.

PPARs are promising therapeutic target for treatment of IR and T2D. They control differentiation and development of adipocytes via gene expression. PPAR $\alpha$ activators eliminate IR condition and its consequences. PPAR activation requires a ligand. Synthetic ligands are already used for treatment of diabetes, but they have several side effects. Research and investigation of endogenous substances i.e. PPAR ligands is an urgent task. Synthetic PPAR ligands directly increase sensitivity to insulin, formation of new fat cells and improve inflammation condition, associated with hypertrophic adipocytes, but the side effect is progression of hyperplastic obesity. Scientific research and investigation of selective PPAR modulators, as well as development of agonists, the effect of which covers two or even all three PPAR isoforms, are carried out. They should provide the possibility to neutralize TZD adverse effects.

$\mathrm{N}$-acylethanolamines represent a group of endogenous substances of endocannabinoid system. Representatives of these substances possess broad spectrum of biological activity, associated with their ability to interact and bind receptors activated via proliferator peroxide PPAR. 


\section{References}

1. Shaw JE, Sicree RA, Zimmet PZ. Global estimates of the prevalence of diabetes for 2010 and 2030 . Diabetes Res Clin Pract 2010;87(1):4-14. https://doi.org/10.1016/j.diabres.2009.10.007

2. Duong TV, Shih CK, Wong TC, Chen HH, Chen TH, Hsu YH, Peng SJ, Kuo KL, Liu HC, Lin ET, Su $\mathrm{CT}$, Yang SH. Insulin Resistance and Cardiovascular Risks in Different Groups of Hemodialysis Patients: A Multicenter Study. Biomed Res Int. 2019;2019:1541593.

https://doi.org/10.1155/2019/1541593

3. Robins SJ, Lyass A, Zachariah JP, Massaro JM, Vasan RS. Insulin resistance and the relationship of a dyslipidemia to coronary heart disease. Arterioscler Thromb Vasc Biol 2011; 31(5):1208-14. https://doi.org/10.1161/ATVBAHA.110.219055

4. Hula NM. Fatty Acids and Their Derivatives in Pathologic States. Kyiv Naukova dumka, 2009.

5. Morigny P, Houssier M, Mouisel E, Langin D. Adipocyte lipolysis and insulin resistance. Biochimie 2016;125:259-66.

https://doi.org/10.1016/j.biochi.2015.10.024

6. Klevebro S, Juul SE, Wood TR. A More Comprehensive Approach to the Neuroprotective Potential of Long-Chain Polyunsaturated Fatty Acids in Preterm Infants Is Needed-Should We Consider Maternal Diet and the n-6:n-3 Fatty Acid Ratio Front Pediatr. 2020;7:533.

https://doi.org/10.3389/fped.2019.00533

7. Bays HE, Toth PP, Kris-Etherton PM, Abate N, Aronne LJ, Brown WV, Gonzalez-Campoy JM, Jones SR, Kumar R, La Forge R, Samuel VT. Obesity, adiposity, and dyslipidemia: a consensus statement from the National Lipid Association. J Clin Lipidol 2013;7(4):304-83. https://doi.org/10.1016/j.jacl.2013.04.001

8. Deedwania P. Hypertension, dyslipidemia, and insulin resistance in patients with diabetes mellitus or the cardiometabolic syndrome: benefits of vasodilating $\beta$-blockers. J Clin Hypertens (Greenwich) 2013;13(1):52-9. https://doi.org/10.1111/j.1751-7176.2010.00386.x

9. Coelho M, Oliveira T, Fernandes R. Biochemistry of adipose tissue: an endocrine organ. Arch Med Sci 2013;9(2):191-200.

https://doi.org/10.5114/aoms.2013.33181

10. Akbari M, Hassan-Zadeh V. IL-6 signalling pathways and the development of type 2 diabetes. Inflammopharmacology 2018; 26(3):685-698. https://doi.org/ 10.1007/s10787-018-0458-0

11. Matias I, Gonthier MP, Petrosino S, Docimo L, Capasso R, Hoareau L, Monteleone P, Roche R, Izzo AA, Di Marzo V. Role and regulation of acylethanolamides in energy balance: focus on adipocytes and beta-cells. $\mathrm{Br} \mathrm{J}$ Pharmacol 2007;152(5):676-90.

https://doi.org/10.1038/sj.bjp.0707424

12. Bruun S, Gouveia-Figueira S, Domellöf $M$, Husby S, Neergaard Jacobsen L, Michaelsen KF, Fowler CJ, Zachariassen G. Satiety factors oleoylethanolamide, stearoylethanolamide, and palmitoylethanolamide in mother's milk are strongly associated with infant weight at four months of age-data from the odense child cohort. Nutrients. 2018;10(11):1747.

https://doi.org/10.3390/nu10111747 
13. Glass CK, Olefsky JM. Inflammation and lipid signaling in the etiology of insulin resistance. Cell Metab 2012;15(5):635-45.

https://doi.org/10.1016/j.cmet.2012.04.001

14. Grigorieva SM, Starosyla DB, Rybalko SL, Motronenko VV, Lutsenko TM, Galkin OYu. Effect of recombinant human interleukin-7 on Pseudomonas aeruginosa wound infection. Ukr Biochem J 2019;91(5):7-15.

https://doi.org/10.15407/ubj91.05.007

15. Peritore AF, Siracusa R, Crupi R, Cuzzocrea S. Therapeutic Efficacy of Palmitoylethanolamide and Its New Formulations in Synergy with Different Antioxidant Molecules Present in Diets. Nutrients 2019;11(9):2175.

https://doi.org/10.3390/nu11092175

16. Lutsenko TN, Kovalenko MV, Galkin OYu Validation of biological activity testing procedure of recombinant human interleukin-7. Ukr Biochem J 2017;89(1):82-9. https://doi.org/10.15407/ubj89.01.082

17. Herheliuk T, Perepelytsina O, Ostapchenko L, Sydorenko M. Effect of Interferon $\alpha-2 b$ on Multicellular Tumor Spheroids of MCF-7 Cell Line Enriched with Cancer Stem Cells. Innov Biosyst Bioeng 2019;3(1):34-44.

https://doi.org/10.20535/ibb.2019.3.1.157388

18. Shi J, Fan J, Su Q, Yang Z. Cytokines and Abnormal Glucose and Lipid Metabolism. Front Endocrinol (Lausanne). 2019;10:703. https://doi.org/10.3389/fendo.2019.00703

19. Qatanani M, Lazar MA. Mechanisms of obesityassociated insulin resistance: many choices on the menu. Genes Dev 2007;21(12):1443-55. https://doi.org/10.1101/gad.1550907

20. Grundy SM. Hypertriglyceridemia, insulin resistance, and the metabolic syndrome. Am J Cardiol 1999;83(9B):25F-29F.

https://doi.org/10.1016/s0002-9149(99)00211-8

21. Saleh S, El-Maraghy N, Reda E, Barakat W. Modulation of diabetes and dyslipidemia in diabetic insulin-resistant rats by mangiferin: role of adiponectin and TNF- $\alpha$. An Acad Bras Cienc 2014;86(4):1935-48.

https://doi.org/10.1590/0001-3765201420140212

22. Yang X, Zhang S, Dong Z, Zi Y, Luo Y, Jin Z, Shi $\mathrm{L}, \mathrm{Li} \mathrm{C}$, Ren C, Wu D. Insulin Resistance Is a Risk Factor for Overall Cerebral Small Vessel Disease Burden in Old Nondiabetic Healthy Adult Population. Front Aging Neurosci. 2019;11:127. https://dx.doi.org/10.3389/fnagi.2019.00127

23. Tangvarasittichai S. Oxidative stress, insulin resistance, dyslipidemia and type 2 diabetes mellitus. World J Diabetes 2015;6(3):456-80. https://doi.org/10.4239/wjd.v6.i3.456

24. Al-Mahmood AK, Afrin SF, Hoque N. Dyslipidemia in insulin resistance: cause or effect. Bangladesh J Med Biochem 2014; 7(1): 27-31. https://doi.org/10.3329/bjmb.v7i1.18576

25. Jung H, Chae HK. The safety and efficacy of methocarbamol as a muscle relaxant with analgesic action: analysis of current data. Innov Biosyst Bioeng 2019;3(4):201-11.

https://doi.org/10.20535/ibb.2019.3.4.183336

26. Raphael W, Sordillo LM. Dietary polyunsaturated fatty acids and inflammation: the role of phospholipid biosynthesis. Int J Mol Sci 2013;14:21167-88. https://doi.org/10.3390/ijms141021167

27. Gula NM, Goridko TM, Stogniy NA, Klymashevsky VM, Meged OF, Kosyakova GV, Shovkun SA, Kindruk NL, Berdyshev AG. Protective effect of n-stearoylethanolamine under acute alcohol intoxication in rats. Ukr Biochem J 2010;82(2):42-52.

28. Andreieva SV, Korets KV. Results of Cytogenetic and Molecular Cytogenetic Studies in Relapce/Refractory of Multiple Myeloma. Innov Biosyst Bioeng. 2018;2(4):213-20. (in Ukrainian) https://doi.org/10.20535/ibb.2018.2.4.143938

29. Galkin O.Yu., Savchenko A.A., Nikitina K.I., Dugan O.M. Obtaining and study of properties of new monoclonal antibodies against human $\operatorname{IgE}$. Ukr Biochem J 2013;85(5):81-87.

http://dx.doi.org/10.15407/ubj85.05.081 
30. Galkin OYu, Lutsenko TM, Gorshunov YuV, Motronenko VV. Development of the method for microbiological purity testing of recombinant human interleukin-7-based product. Ukr Biochem J 2017;89(3):52-9. https://doi.org/10.15407/ubj89.03.052

31. Onopchenko OV, Kosiakova GV, Goridko TM, Berdyschev AG, Meged OF, Hula NM. The effect of N-stearoylethanolamine on the activity of antioxidant enzymes, content of lipid peroxidation products and nitric oxide in the blood plasma and liver of rats with induced insulin-resistance. $\mathrm{Ukr}$ Biochem J 2013;85(5):88-96. https://doi.org/10.15407/ubj85.05.088

32. Hula NM, Marhitych VM, Horidko TM, Artamonov MV, Zhukov OD, Klimashevskyi VM. Method for producing n-acylethanolamines. Ukrainian patent 81861. 2008.

33. Zhukov AD, Berdyshev AG, Kosiakova GV, Klimashevskiy VM, Gorid'ko TM, Meged OF, Hula NM. N-stearoylethanolamine effect on the level of 11-hydroxycorticosteroids, cytokines IL$1 \beta$, IL-6 and TNF $\alpha$ in rats with nonspecific inflammation caused by thermal burn of skin. Ukr Biochem J 2014;86(3):88-97.

https://doi.org/10.15407/ubj86.03.088

34. Lim HY, Müller N, Herold MJ, van den Brandt J, Reichardt HM. Glucocorticoids exert opposing effects on macrophage function dependent on their concentration. Immunology 2007;122(1):47-53. https://doi.org/10.1111/j.1365-2567.2007.02611.x

35. Galkin OYu, Gorshunov YuV, Besarab OB, Ivanova OM. Development and characterization of highly informative ELISA for the detection of IgG and IgA antibodies to Chlamydia trachomatis. Ukr Biochem J 2018;90(3):49-62.

https://doi.org/10.15407/ubj90.03.070

36. Goridko TM, Kosiakova GV, Berdyschev AG, Bazylyanska VR, Margitich VM, Gula NM. The influence of N-stearoylethanolamine on the activity of antioxidant enzymes and on the level of stable NO metabolites in the rat testes and blood plasma at the early stages of streptozotocineinduced diabetes. Ukr Biochem J 2012;84(3):37-43.

37. Velkov VV. Free fatty acids: the new marker of insulin resistance and ischemia. Laboratornaia diagnostika 2009;3(49):55-71. (In Russian)

38. Galkin OYu, Besarab AB, Lutsenko TN. Characteristics of enzyme-linked immunosorbent assay for detection of IgG antibodies specific to Chlamydia trachomatis heat shock protein (HSP60). Ukr Biochem J 2017;89(1):22-30. https://doi.org/10.15407/ubj89.01.022

39. Rull A, Camps J, Alonso-Villaverde C, Joven J. Insulin resistance, inflammation, and obesity: role of monocyte chemoattractant protein-1 (or CCL2) in the regulation of metabolism. Mediators Inflamm 2010;2010:326580. https://doi.org/10.1155/2010/326580

40. Onopchenko OV. The effect of Nstearoylethanolamine on plasma lipid composition in rats with experimental insulin resistance. Ukr Biochem J 2015;87(1):46-54. https://doi.org/10.15407/ubj87.01.046

41. Zhou H, Urso CJ, Jadeja V. Saturated Fatty Acids in Obesity-Associated Inflammation. J Inflamm Res. 2020;13:1-14. https://doi.org/10.2147/JIR.S229691

42. Galkin O.Yu., Komar A.G., Besarab O.B. Different mice inbred strains humoral immune response against human prostate-specific antigen. Ukr Biochem J 2019;91(1):30-7. https://doi.org/10.15407/ubj91.01.030

43. Onopchenko OV, Kosiakova GV, Meged EF, Klimashevsky VM, Hula NM. The effect of Nstearoylethanolamine on cholesterol content, fatty acid composition and protein carbonylation level in rats with alimentary obesity-induced insulin resistance. Ukr Biochem J 2014;86(6):119-28. https://doi.org/10.15407/ubj86.06.119 


\title{
Metabolički sindrom i poremećaji metabolizma masti: molekularni i biohemijski aspekti
}

\author{
Oksana Tkachenko ${ }^{1}$, Iryna Polishchuk², Nadiya Gorchakova ${ }^{3}$, Hanna Zaychenko ${ }^{3}$ \\ ${ }^{1}$ Institit za biohemiju Paladin, Kijev, Ukrajina \\ 2Politehnički institut "Igor Sikorsky" Kijev, Kijev, Ukrajina \\ ${ }^{3}$ Nacionalni medicinski univerzitet Bogomolets, Kijev, Ukrajina
}

S A ŽET A K

Ovaj revijski rad prikazuje karakteristike adipoznog tkiva, kao metabolički aktivnog organa, ukazuje na endokrine funkcije adipoznog tkiva, $i$ predstavlja ulogu adipoznog tkiva $u$ funkcionisanju imunog sistema. Takođe, prikazana je uloga gojaznosti u razvoju insulinske rezistencije i dijabetesa melitusa tipa 2, i prikazan je efekat dislipidemije na razvoj metaboličkog sindroma i insulinsku rezistenciju. Pokazano je da je osnovna funkcija masnog tkiva skladištenje enrgije preko održavanja ravnoteže između lipolize i lipogenetskih procesa. Inhibicija lipogeneze i uvećanje lipolize posmatrani su u metaboličkim poremećajima, naročito u insulinskoj rezistenciji. Funkcija adipoznog tkiva reguliše se putem adipokina, koji se tu i luče. Stanje inflamacije suštinski je konstituent $i$ jedan je od razloga statusa insulinske rezistencije. Neutralizacija glavnih inflamatornih citokina ne obnavlja senzitivnost na insulin, što ukazuje na činjenicu da stanje upale nije jedini uzrok insulinske rezistencije. Hronična inflamacija niskog stepena razvija se kao rezultat gojaznosti. Proinflamatorni citokini utiču na insulinsko signaliziranje putem stimulacije stres kinaza._Funkcije signalnih i imunih ćelija zavise od fosfolipidnog sastava.

Nezasićene masne kiseline su supstrat sinteze bioaktivnih medijatora. Dodeljeni aktivirani receptori proliferacije peroksizoma (PPARs) smatraju se glavnim terapeutskim ciljem. Takođe, ispitani su sintetički ligandi tiazolidindona, kao i komponente endogenog kanabinoidnog sistema $\mathrm{N}$-acetiltanolamina. $\mathrm{N}$ steroletanolamin je od posebne važnosti; takođe, prikazan je njegov pozitivni efekat na normalizaciju lipidnog profila različitih tkiva, naročito tkiva osetljivih na insulin.

Ključne reči: adipozno tkivo, gojaznost, dijabetes melitus tipa 2, insulinska rezistencija, masne kiseline, endokanabinoidne supstance 